\title{
Analyzing the Reasons for Patients Opting-out from Root Canal Treatment and Preferring Extraction in South Indian Population-Prospective Study
}

\author{
${ }^{1}$ Kadandale Sadasiva, ${ }^{2}$ Sreeram Rayar, ${ }^{3}$ Kumarappan Senthilkumar, ${ }^{4}$ Manu Unnikrishnan, ${ }^{5}$ Udayakumar Jayasimharaj
}

\section{ABSTRACT}

Aim: To evaluate the reasons behind patients opting out from root canal treatment (RCT) and undergoing extraction in south Indian population.

Materials and methods: Data of 561 patients reported to the department of conservative dentistry and endodontics from the period 1st January 2013 to 31st December 2017 for the treatment of irreversible pulpitis and who eventually decided for extraction were collected. The questionnaires were sent to the patient and collected. The reasons documented were entered into Statistical Package for the Social Sciences (SPSS) statistical software for statistical analysis. The results subjected to frequency distribution tests.

Results: The study reveals the primary reason for the patient not undergoing RCT were misbelief in the success of RCT 14.97\%, followed by cost factor $13.90 \%$ and for immediate pain relief following extraction $13.19 \%$.

Conclusion: The patient's misbelief associated with the failure of RCT was the major reason for the patients to opt out of RCT and preferring extraction.

Clinical significance: The psychology of the patients in regard towards the root canal treatment can be clearly understood by this study. The article gives an insight into the acceptance and rejection of RCT by patients and therefore helping dentists/ specialists in formulating better treatment plans according to the patient needs.

Keywords: Dental anxiety, Misbelief, Patient counseling, and education, Planning, and patient preferences, Root canal treatment, Tooth extraction.

How to cite this article: Sadasiva K, Rayar S, Senthilkumar $\mathrm{K}$, Unnikrishnan M, Jayasimharaj U. Analyzing the Reasons for Patients Opting-out from Root Canal Treatment and Preferring Extraction in South Indian Population-Prospective Study. Int J Prosthodont Restor Dent 2018;8(4):108-113.

${ }^{1}$ Professor, ${ }^{2}$ Senior Lecturer, ${ }^{3,5}$ Professor and HOD, ${ }^{4}$ Reader

${ }^{1-4}$ Department of Conservative Dentistry and Endodontics, Chettinad Dental College and Research Institute, Kanchipuram, Tamil Nadu, India

${ }^{5}$ Department of Dentistry, Trichy SRM Medical College and Research Centre, Irungalur, Tamil Nadu, India

Corresponding Author: Kadandale Sadasiva' Professor Department of Conservative Dentistry and Endodontics, Chettinad Dental College and Research Institute, Kanchipuram, Tamil Nadu, India, Phone: 9791096355, e-mail: drsadasiva2@ gmail.com
Source of support: Nil

Conflict of interest: None

\section{INTRODUCTION}

Dental caries is one of the commonest dental diseases affecting mankind and its sequel if untreated on time leads to irreversible pulpitis causing pain and swelling which brings the patient to the dentist. According to the American Association of Endodontists (AAE), a root canal is a dental procedure indicated for the treatment of damaged or infected teeth with irreversible pupal pathosis. Root canals save more than 40 million teeth in the United States every year. When people have infections of the root pulp, the two main treatments are root canal therapy or extraction. In this renaissance era of endodontics saving the tooth by root canal therapy is more predictable and its rate of success is around $95 \%$. Although initial root canal treatment should have a success rate between 85 and $97 \%$, depending on the circumstance with the usage of operating microscopes, the success rate of endodontics is high about 73 to $99 \%$, depending on the criteria used for evaluating success. ${ }^{1,2}$

Although clinical studies show increased success, some number of patients opt out of RCT and undergo extraction which results in loss of a tooth, and subsequent events lead to collapsed occlusion and prosthesis which increases the economic burden and mortality of other teeth. $^{3}$

This study was done to analyze the reasons for patients opting out for root canal treatment and selecting extraction as treatment of choice in south Indian population.

\section{MATERIALS AND METHODS}

In this study, dental records of 590 patients who attended outpatient department in Chettinad Dental College and Research Institute, Kelambakkam, Tamil Nadu, India, throughout five years from 1st January 2013 to 31st December 2017 were selected in the study who meets inclusion and exclusion criteria of the study.

Nonprobability, convenient sampling designs were employed. The patients who opted for extraction rather than RCT were chosen in the study. A pretested selfadministered questionnaire was used to measure the 
patient's reasons to opt out of RCT provided by the dental hospital. The total of 12 close-ended questions was used. Patients were also given the option to mention any other reason other than asked. Items covered were negative opinions, cost and time factors regarding RCT. Face and content validity was 0.75 , and the internal consistency of the questions was $\alpha=0.75$

Five hundred ninety dental records were evaluated, and 561 were selected based on inclusion and exclusion criteria. The questionnaire was sent to patients address after telephonic consent and questionnaires filled were collected back through post using business reply envelopes and responses were recorded and subjected to statistical analysis. The results subjected to frequency distribution tests.

The study was a cross-sectional study including the subjects from the majority of dental colleges situated in South India, which constitutes Karnataka, Kerala, Andhra Pradesh, Puducherry, and Tamil Nadu. The state of Tamil Nadu was chosen randomly because it comprises the only metropolitan city Chennai among the southern states of India. Among the 29 dental colleges ${ }^{3}$ in the state of Tamil Nadu, one dental teaching hospital (Chettinad Dental College and research institute, Kanchipuram) was randomly selected. Ethical approval was obtained from the institutional Human Ethics Committee, Department of Chettinad Academy of Research and Education with letter number 139/IHEC/06-18.

\section{Inclusion Criteria}

- Patient having dental caries with symptoms of irreversible pulpitis

- Fully erupted teeth

- Teeth with restorable prognosis

\section{Exclusion Criteria}

- 3rd molars, not fully erupted teeth,

- Tooth with grade III, II Mobility,

- Radiographically extensive bone loss,

- Medically compromised patients,

- Patients having trismus,

- Teeth that cannot be restored

\section{RESULTS}

Distribution of patients according to reasons to drop out of RCT was presented in Graph 1. Among the patients, $14.97 \%$ (84) of patients felt that the RCT is a failure treatment, $7.84 \%$ (44) of patients felt that the tooth needs to be extracted after RCT, 3.03\%(17) of patients felt that RCT will cause cancer and other health issues, $13.90 \%$ (78) of patients felt that the cost of RCT and crown was high, $10.33 \%$ (58) of patients felt that more appointments with pain will require for RCT, $4.99 \%$ (28) of patients felt that they opted for implants, $13.01 \%$ (73) of patients felt that compromised prognosis was given by dentist, $13.19 \%$ (74) of patients felt that they require immediate pain relief but not worried about tooth loss, 3.03\% (17) of patients are moving abroad, $4.27 \%$ (24) of patients felt they cannot be cooperative and prolonged treatment periods, 3.03\% (17) of patients felt that they are too old for RCT and requesting extraction and $4.09 \%$ (23) of patients felt that they had previous bad experience from RCT and 4.27\% (24) opted out because its a back tooth and were not bothered too much.

\section{DISCUSSION}

Patients' pretreatment decisions and post-treatment satisfaction may be strongly influenced by social, psychological,

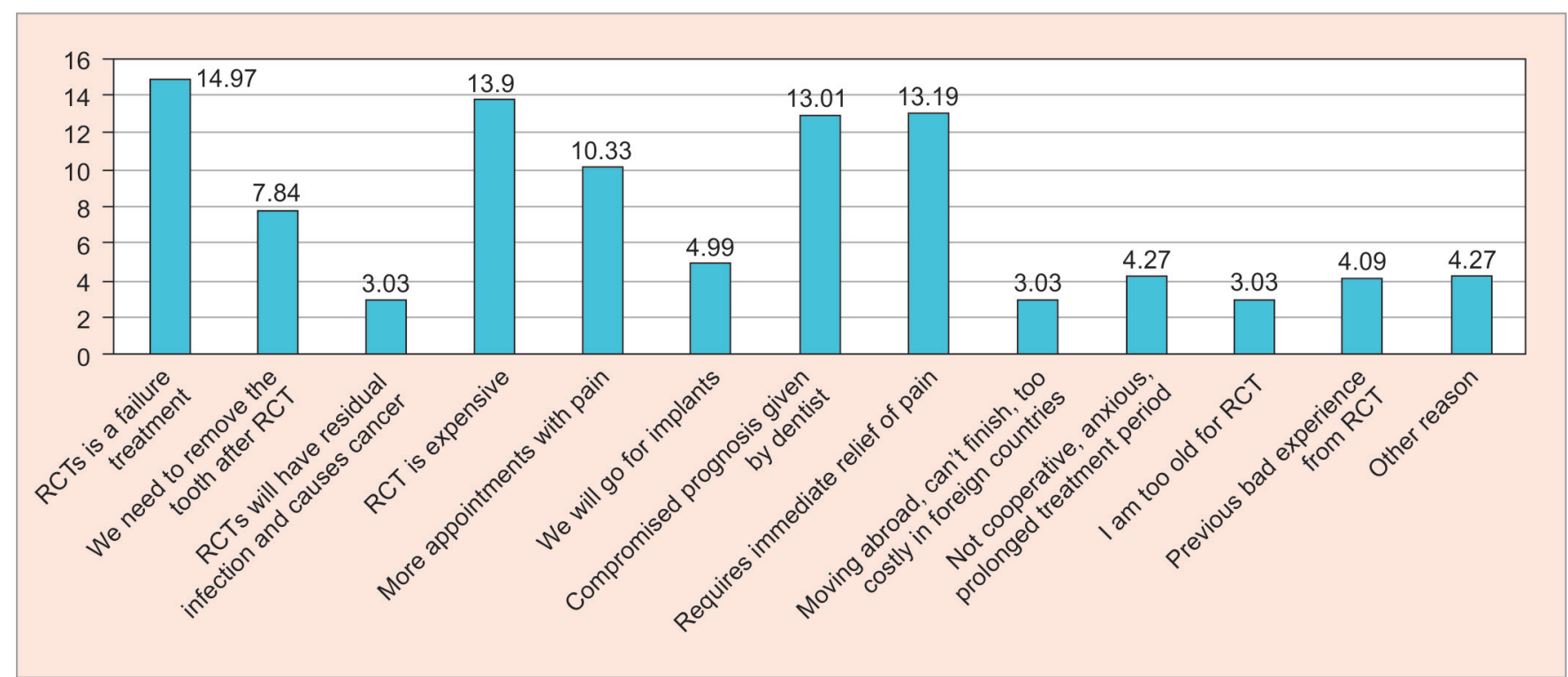

Graph 1: Distribution of patients according to reasons to drop out of RCT 
and behavioral dimensions including knowledge, beliefs, attitudes and their preference. ${ }^{4}$ Friedman et al. reported $78 \%$ complete healing and $16 \%$ incomplete healing after non surgical root canal treatment which would be $94 \%$ because of the "Lenient criteria. ${ }^{5,6}$ Considering the favorable outcome, both nonsurgical and surgical endodontic therapy is justified and should be attempted when a good restorative and periodontal prognosis is projected, unless the patient is not motivated to retain the tooth. ${ }^{5}$ Gõrduysus et al. stated that about $15 \%$ of the patients were in favor of extraction versus RCT before the therapy. ${ }^{7}$

Patients searching the internet for information on root canals may find sites claiming that teeth receiving root canal treatment contribute to the occurrence of illness and disease in the body. It originated from the research of Weston Price, a dentist in the early 20th century who ran a series of flawed and poorly designed tests. ${ }^{8}$ Mentally preparing a patient for root canal and counseling against the myth is of utmost importance in saving the natural dentition.

Root canal treatment is highly cost-effective as a first line intervention. ${ }^{9}$ The cost for replacing an extracted tooth is higher in all countries when comparing with root canal treatment followed by its prosthetic rehabilitation. This cost factor should be conveyed to the patient and motivated for RCT. Patients who need endodontic treatment are often burdened by two main concerns, the length of the procedure and pain. ${ }^{10}$ The experience of pain associated with RCT is a major source of fear and concern for dentists, particularly in cases with preoperative symptoms. $^{11}$

Endodontic treatment is often accompanied by negative connotations, however, among the patients who underwent endodontic treatment, only 17\% described it as an extremely painful experience, and 96.3\% agreed to the re-intervention. ${ }^{12,13}$ The key factors that lead to a pleasant environment for endodontic treatment are pain prevention, positive interaction, words of encouragement and a sense of control over the situation.

The most intense form of the fear of the dentist is dental phobia. ${ }^{12,14}$

Psychological approaches such as behavioral therapy and hypnotherapy represent a higher level of pain control, after which the patients showed a statistically significant reduction of fear, measured with dental anxiety scale (DAS). However, these methods require care and a systematic commitment to the patient, factors the implementation of which is questionable in dentists' daily work. ${ }^{12,14-16}$

Pennington et al. ${ }^{9}$ in his studies concluded that modeling the available clinical and cost data indicates RCT as a primary intervention. Orthograde re-treatment is also cost-effective in case a root treatment subsequently fails.
Implants may have a role as a third line intervention only if re-treatment of RCT fails. In all the cases RCT is preferred over implants to retain natural dentition. Some clinical situations may not guarantee lifetime clinical success, and might requires alternate treatment plans. This compromised prognosis sometimes may not be accepted by the patient and resort to some permanent solution like implants and fixed bridges.

Nearly $13.19 \%$ of the patients who participated in the survey are not worried about tooth loss and required immediate pain relief, and these patients need counseling regarding the retention of natural teeth and the cost of the prosthesis in replacing the extracted teeth.

About $3.03 \%$ of the participants wanted extraction as their choice because they are moving abroad and cannot complete root canal treatments and prosthesis and continuing it in developed countries as it may be costlier when compared to developing countries like India; $4.27 \%$ of the patients opted for extraction because of long appointments, anxiety and were non-cooperative. The data showed that dentally anxious individuals were more likely to be edentulous, and among the dentate, had more missing and fewer filled teeth. As a result, dentally anxious dentate subjects were more likely to need prosthodontic treatment. ${ }^{17}$ Patients may avoid RCT due to anxiety and fear of pain, resulting in treatment avoidance and eventual tooth loss through extractions. ${ }^{17}$

About $3.03 \%$ of the patients opted out of RCT as they feel that they cannot come for multiple visits and prolonged treatment periods since they are old. They also feel its too exhaustive for geriatric patients, traveling and bystander arrangements. Some of the systemic disorders such as Parkinsonism, orthostatic hypertension makes still worse. Cost factor and slow healing were also one of the reasons. Short appointments with the use of gadgets for neck and back support in such cases provide reassurance for the success of the treatment. ${ }^{18}$

About $4.09 \%$ opted out from RCT despite the progress in the way of conducting dental procedures and methods of pain control, and most patients describe a visit to the dentist as a painful and unpleasant experience. ${ }^{19-22}$ Psychological characteristics of people and the potentially negative experience overpower the objective state of the patient regarding the procedure. This creates a vicious circle of anxiety and pain, with a tendency of the two to increase., 9,12 Proper anesthesia and pain management techniques and reassurance will help to gain the confidence of the patients.

Other reasons cited by the patients were that by extracting one or two posterior teeth causes little or no functional impairment. Endodontic treatment in molars are more expensive than that of anterior teeth, and the motivation for the treatment from the patient side is less intense because of the belief that little or no functional 
impairment or aesthetics may ensure following extraction of one or two posterior teeth. ${ }^{23}$ Dentists should educate the patient regarding the importance of posterior teeth in mastication, maintaining the arch and occlusion.

A thorough review of literature done by Estrela et al. ${ }^{24}$ analyses the relevant factors associated with patients health, tooth and dentist that could account for a successful RCT. According to AAE, ${ }^{25}$ professional videos illustrating the success, safety, and accuracy of RCTs and advanced gadgets like cone beam computed tomography (CBCT) to locate pain accurately will educate the patient, and other related treatments will improve the acceptance of RCTs. In recent years in Endodontics, there has been a real explosion of new technologies, new instruments and new materials which made many procedures especially RCT more predictable and accurate. The most important revolution is the use of the surgical operating microscope and CBCT. Dentistry is moving away from "radiographic interpretation" in to "disease visualization". With all these revolutionary progress, the long term success rate of RCTs is higher and more predictable. ${ }^{26}$ One study indicated ${ }^{27}$ that the most common reason for the extraction of endodontically treated teeth was for prosthetic reasons. The effective irrigant delivery and agitation leading to effective cleanliness are prerequisites for successful endodontic treatment. This systematic review presents an overview of the irrigant agitation methods currently available and their debridement efficacy. clinicians and the patients also do not want to risk having a possible problematic tooth under the prosthesis because of economic and personal reasons. Careful treatment planning and execution will improve the acceptance of RCTs. Recent study by Yamaguchi et al. ${ }^{28}$ reveals all the possible factors responsible for root canal failures which give insight for the dentists to avoid all listed reasons and to improve the success of RCTs. One recent systematic review ${ }^{29}$ presents an overview of the irrigant agitation methods currently available and their debridement efficacy. Effective irrigant delivery and agitation leading to effective cleanliness are prerequisites for successful endodontic treatment. By understanding the patient expectations and the recent advances in instruments and technologies leads to more predictable success in RCT.

\section{CONCLUSION}

After analyzing the reasons thoroughly and understanding the needs of the patients, a number of teeth can be saved by performing RCT rather than extraction leading to good quality of life (QOL) thus preserving natural dentition. Findings of this study suggest patients education to remove their false belief about endodontic treatment and improve the acceptance of RCTs.

\section{CLINICAL SIGNIFICANCE}

The psychology of the patients in regard towards the root canal treatment can be clearly understood by this study. The article clearly gives an insight into the acceptance and rejection of RCT by patients and therefore helping dentists / specialists in formulating better treatment plans according to the patient needs.

\section{REFERENCES}

1. http://www.elmendo.com/2012/01/do-root-canals-work/v (Last accessed on 30/10/2018,-13.44).

2. Gross man's Endodontic practice, $12^{\text {th }}$ edition,B.Suresh Chandra,V. Gopikrishna, p 390.

3. http://www.dciindia.org.in/CollegeSearch.aspx?ColName $=\&$ CourseId $=\&$ SplId $=0 \&$ StateId $=$ TAM $\&$ Hospital $=\&$ Typ e=0\&Status=--Select-- ( last access on 20-10-2018 $10: 23$ AM).

4. Vaughn LM, Jacquez F, Baker RC. Cultural health attributions, beliefs, and practices: effects on healthcare and medical education. Open Medl Edu J. 2009;2:64-74.

5. Friedman S, Mor C. The success of endodontic therapy-healing and functionality. J Calif Dent Assoc. 2004 Jun;32(6):493-503.

6. Friedman S, Mor C. The success of endodontic therapy-healing and functionality. J Calif Dent Assoc. 2004 Jun;32(6):493-503.

7. Gõrduysus MO, Gõrduysus MG. Endodontic patient profile of Hacettepe university, faculty of dentistry in Ankara, Turkey. Int Dent J. 2000 Oct;50(5):274-278.

8. https://www.healthline.com/health/root-canal-and-cancer (accessed on 27-10-2018 12:50 pm).

9. Pennington MW, Vernazza CR, Shackley P, Armstrong NT, Whitworth JM, Steele JG. Evaluation of the cost-effectiveness of root canal treatment using conventional approaches versus replacement with an implant. Int Endod J 2009;42:874-883.

10. Cunningham CJ, Mullaney TP. Pain control in endodontics. Dent Clin North Am. 1992 Apr;36(2):393-408.

11. Pak JG, White SN. Pain prevalence and severity before, during and after root canal treatment: A systematic review. J Endod. 2011 Apr;37(4):429-438.

12. Van Wijk AJ, Hoogstraten J. Reducing fear of pain associated with endodontic therapy. Int Endod J. 2006 May;39(5):384-388.

13. Vodanović M. Strah od stomatologa. Zdrav život. 2008;57(7): 66-70.

14. Van Wijk AJ, Hoogstraten J. Experience with dental pain and fear of dental pain. J Dent Res. 2005;84(10):947-950.

15. Gale EN, Carlsson SG, Eriksson A, Jontell M. Effects of dentists' behavior on patients' attitudes. J Am Dent Assoc. 1984 Sep;109(3):444-446.

16 Hammarstrand G, Berggeren U, Hackeberg M. Psychophysiological therapy vs. hypnotherapy in the treatment of patients with dental phobia. Eur J Oral Sci. 1995 Dec;103(6): 399-404.

17. Perković I, Romić MK, Perić M, Krmek SJ. Level of anxiety and pain perception of endodontic patients. Acta stomatol Croat 2014;48(4):258-267.

18. Locker D, Liddell A. Clinical correlates of dental anxiety among older adults. Community Dent Oral Epidemiol. 1992 Dec;20(6):372-375.

19. Hamedya R, Shakibaa B,v Fayazi S, Paka JG,v White SN. Patient-centered endodontic outcomes: A narrative review. Iranian Endod J 2013;8(4):197-204 
20. Hägglin C, Hakeberg M, Ahlqwist M, Sullivan M, Berggren U. Factors associated with dental anxiety and attendance in middle-aged and elderly women. Community Dent Oral Epidemiol. 2000 Dec;28(6):451-460.

21. Klages U, Ulusoy Ö, Kianifard S, Wehrbein H. Dental trait anxiety and pain sensitivity as predictors of expected and experienced pain in stressful dental procedures. Eur J Oral Sci. 2004 Dec;112(6):477-483.

22. Donaldson D. Anxiety: its management during the treatment of the adolescent dental patient. Int Dent J. 1982 Mar;32(1): 44-55.

23. Umanah AU, Osagbemiro BB,Arigbede AO. Pattern of demand for endodontic treatment by adult patients in PortHarcourt, South- South Nigeria. J West Afr Coll Surg. 2012 Jul-Sep;2(3):12-23.

24. Estrela C, Holland R, Estrela CR, Alencar AH, Sousa-Neto MD, Pécora JD. Characterization of successful root canal treatment. Braz Dent J 2014;25(1)3-11.
25. https://www.aae.org/specialty/practice-management/ managing-a-practice/practice-marketing/patient-professional-videos/. Last accessesed on 25/12/2018,8.01am

26. Malentacca A, Castellucci A. Problem solving within the scope and challenges of endodontic procedures. https:// endodontics.it/2018/ wp-content/uploads/2018/09/ AbstractBook_Milano 2018.pdf Last accessed on 25/12/2018, 9.48 a.m

27. Olcay K, Ataoglu H, Belli S. Evaluation of related factors in the failure of endodontically treated teeth: A cross-sectional study. J Endod. 2018 Jan;44(1):38-45.

28. Yamaguchi M, Noiri Y, Itoh Y, Komichi S, Yagi K, Uemura R, et al. Factors that cause endodontic failures in general practices in Japan. BMC Oral Health. 2018 Apr;18(1):70.

29. Borse S, Sanap A, Mehta V, Borse N , Bhosale S, Oswal P. Effect of different irrigation devices on removal of smear layer-A systematic review. Int J Contemp Med Res. 2017;4(6):13711377. 


\section{Questionnaire}

Respected Sir/Madam,

You have visited our Dental hospital on and underwent extraction of tooth no.

Please spare a few moments to answer our questions regarding choosing extraction over root canal treatment. Please tick any appropriate reason/multiple reasons. If not write in other reason.

Name: Age/sex :

Income :

Address:

1) Root canal treatment (RCT) is a failure treatment.

2) We need to remove the tooth after RCTs, need some permanent treatment.

3) RCTs will have residual infection, causing heart disease and cancer.

4) Cost of RCT and Crown.

5) More appointments with pain.

6) We will go for implants.

7) Compromised prognosis given by dentist, extract and have prosthesis.

8) Not worried about tooth loss, requires immediate relief of pain.

9) Moving abroad, can not finish, too costly in foreign countries, so extract.

10) Not cooperative, not able to come, prolonged treatment period, withdrawn from treatment patients requesting extraction.

11) Too old for RCT, Requesting extraction.

12) Previous bad experience from RCT.

Other reason:

Signature of the patient 